Amir Sarshin', Hojatollah Nikbakht*1, Khosro Ebrahim $^{2}$, Seyed Mohammad Kazem Vaeze Mosawi $^{3}$

1. Department of Exercise Physiology, Science and Research Branch, Islamic Azad University, Tehran, Iran 2. Department Exercise Physiology, Shahid Beheshti University of Tehran, Iran

3. Imam Hossein University, Tehran, Iran

\section{The Effect of Different Intensity and Duration of Running on Balance in Male Football Player}

Received:17 May 2017 ; Accepted:28 Apr. 2018

The aim of study was to investigate the static and dynamic balance performance after different intensity and duration of running. Fifteen male football player $(a=21.6 \pm 0.9 \mathrm{y}$, $\mathrm{h}=172.4 \pm 6.1 \mathrm{~cm}, \mathrm{w}=68.4 \pm 6.7 \mathrm{~kg}$ ) participated. Conconi test on treadmill and variables of different exercises (Aerobic, Anaerobic, Mixed, Prolonged Intermittent and Super Maximal Intermittent) were measured. Then before and after each exercise participants did Y balance test (YBT), balance error scoring system (BESS), and rating of perceived exertion (RPE). Repeated measure ANOVA was used to data analysis. Results showed no significant difference in double leg position on firm surface after various exercises $(p<0.05)$. However, static balance on firm and foam surfaces in single leg and tandem positions decreased after all exercises $(p<0.05)$. Although, balance impairment was more noticeable after anaerobic, mixed and super maximal intermittent exercises $(p<0.05)$. Dynamic balance declined in three direction after all exercises and the most outstanding decrease occurred after anaerobic exercise in anterior direction $(p<0.05)$. Thus, during balance assessment, intensity and duration of exercise and balance positions should considered evaluating sport performance and clinical application.

Keywords: Dynamic balance, Static Balance, Fatigue

*Corresponding Author: Department of Exercise Physiology, Science and Research Branch, Islamic Azad University, Tehran, Iran

Tel: 0912- 1067749

E-mail: hojnik1937@yahoo.com 


\section{اثر خستكى ناشى از دويدن با شدت و مدت زمان مختلف بر تعادل مردان جوان}

تاريخ دريافت مقاله:99/T/TV ؛ تاريخ پذيرش: 9V/T/N

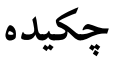

هدف تحقيق بررسى اثر دويدن با شدت و مدت زمان متفاوت بر تعادل ايستا و يويا پِ از شدتها و مدتهـاى متفـاوت

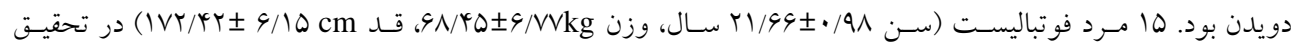

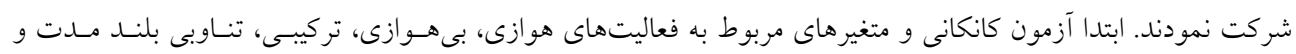

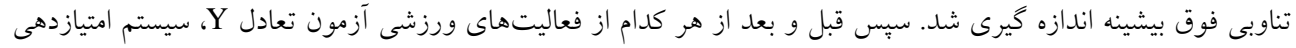

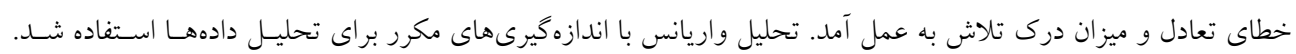

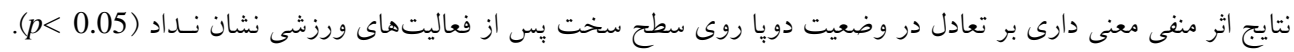

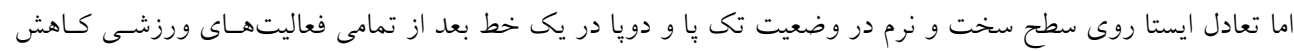

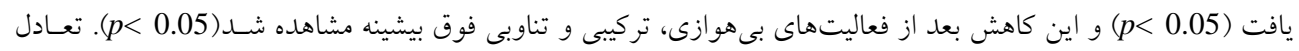

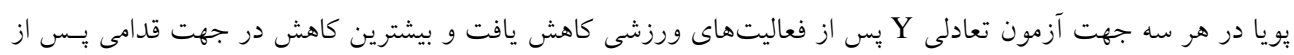

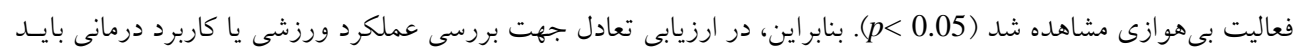
اثر شدت و مدت فعاليتهاى ورزشى و شرايط ارزيابى تعادل مورد توجه قرار كيردا. كلمات كليدى: تعادل يويا، تعادل ايستا، خستخى

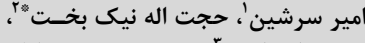

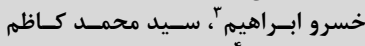

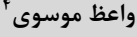

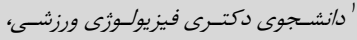

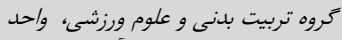

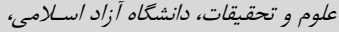

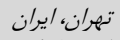

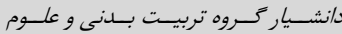

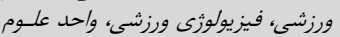

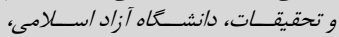
تهران، ايران

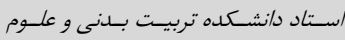

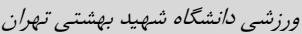

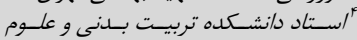
ورزشى دانشاءه امام حسين تهران
"نويسنده مسئول:

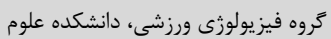

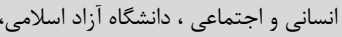

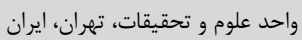

E-mail: hojnik1937@yahoo.com 
موضعى

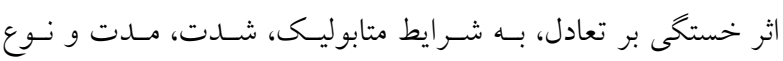

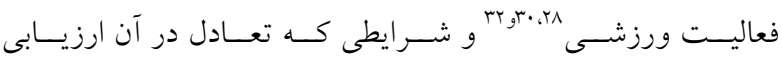

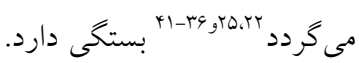

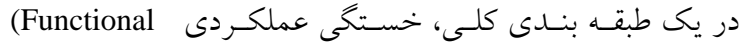
را مىتوان بـا اسـتفاده از فعاليـتهـــــ Fatigue Protocol)

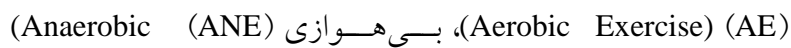
Exercise) و تناوبى فـوق بيشـينه (Prolonged Intermittent Exercise) (PIE) ايجاد نمود. بـا (Super Maximal Intermittent Exercise) (SMIE) اين حال طى بررسى به عمل آمده توسط محققسين، هـيج مطالعـهاى

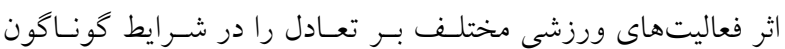
بررسى ننموده است. بيشتر مطالعات اثر خستخى موضعى را بررسى

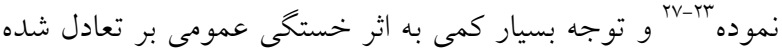
است و اخر خستخى عمومى را بررسى نمودهاند بروتكـل خستيكى

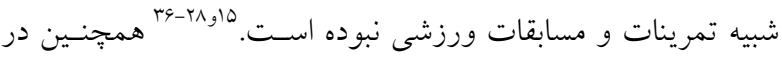
مطالعات از انواع فعاليتهــاى ورزشسى مانتــ دويــن، راه رفـتن و

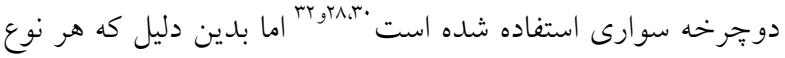

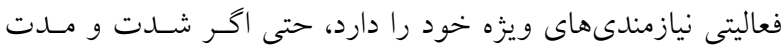
أنها يكسان باشد نمىتوان اثر آنها را با يكسديخر مقايسـه نمـوده. بــهـ

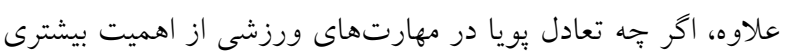

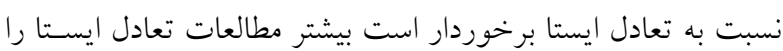

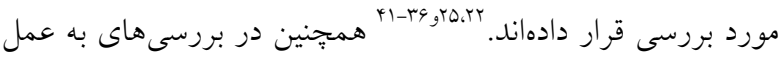

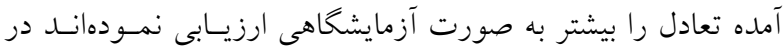
حالى كه جهت دستيابى به نتايج قابل تعميم به شرايط واقعى بهتـر

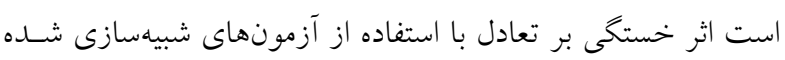
و عملكردى بررسى شود. از سوى ديخر مطالعـات قبلسى اثـــ انـواع

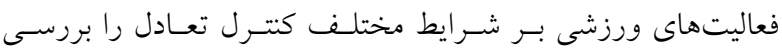

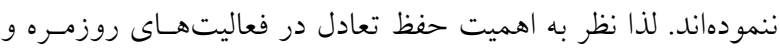
مهارتهاى ورزشى، •ا-1' كاهش تعادل يس از خستخى و در نتيجـه.

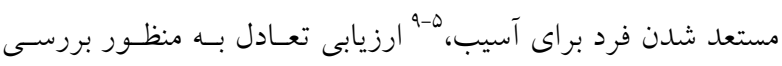

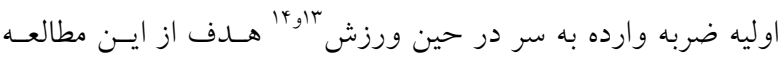

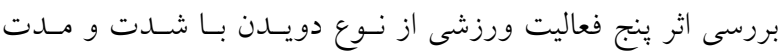
متفاوت بر شرايط مختلـف كنتـرل تعـادل ايسـتا و يويـا در مـردان
مقدمه

كنترل تعادل (Balance Control) و پِايــدارى قامـت Postural)

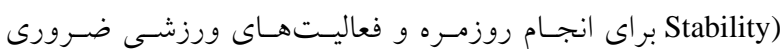
است.' اندازهكيرى تعادل در محسيطهـاى آزمايشـحاهى، ورزشسى و درمانى به عنوان ابزارى جهت ارزيابى كنترل عصـبى - عضـلانى در

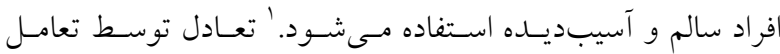
دروندادهــاى حسـس بيكـــى (somatosensory input)، سيسـتم

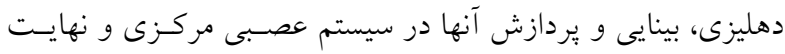

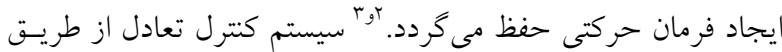

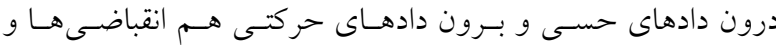
كشتاورهايى در مفاصل ايجاد مسىكنـد تـا حركـت مركـز فشـار در

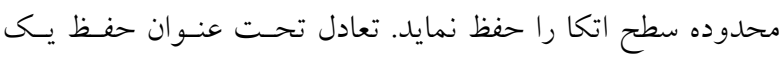

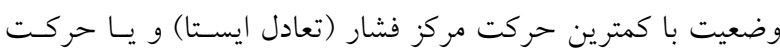
فعال مركز فشار در محدوده سطح اتكا (تعادل يويـا) تعريـف شــــه

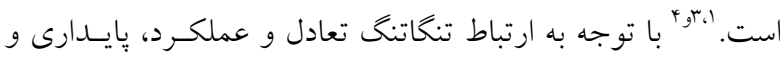

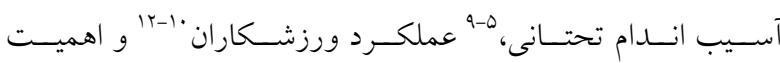

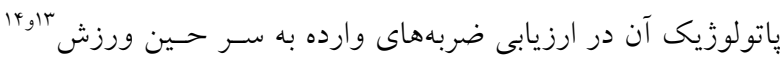
عوامل مداخله كر در سيستم كنترل كنندهى تعادل بررسى شــده انــ. محققان ضعف عضلانى، نقص كيرندهاى عمقى و دامنهى حركتى، سيستم عصبى مركزى معيوب، وضعيت روانى نامطلوب، خستخى و ضربات وارده به سر را به عنوان عوامل مخل سيستم كتتـرل تعـادل

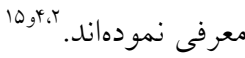

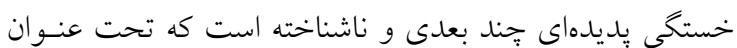
كاهش توان توليدى دلخواه (كاهش نيرو يا سرعت توليـد نيـرو) يـا

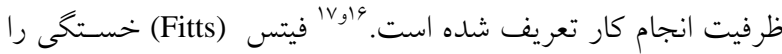

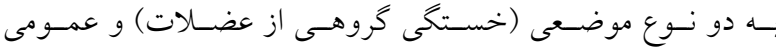

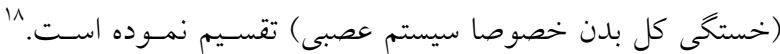
درون دادهاى حسى و فرمانهاى حركتى CNS ممكن اسـت در اثـر

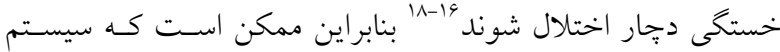
كنترل تعادل را نيز مختل نمايند. همجنــين، خستـى ممكـن اسـت كيرندههاى حسـ عمقسى و حركـت مفاصـل را مختـل نمايسـ، لــا

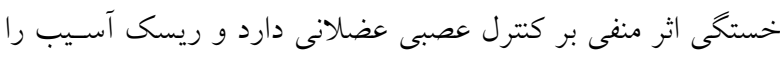

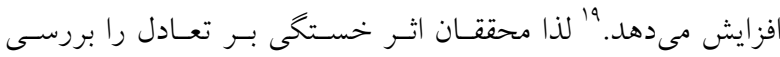

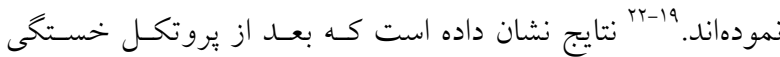


استفاده از آن بروتكل SMIE طراحى شد. سرعت ميانخين با استفاده فوتباليست بود.

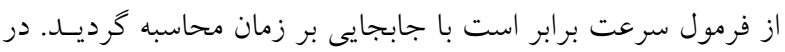

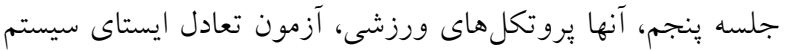
امتيـاز دهـى خطـاى تعـادل)(Balance Error Scoring (BESS) را ياد كرفتنــ و تمـرين نمودنــد. در حسين تمـرين

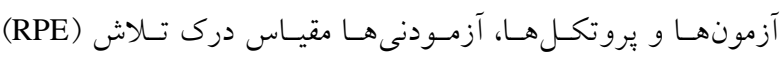
را يـاد گرفتسه و تمـرين كردنـد. (Rating of Perceived Exertion) سيس در طول ينج جلسه با فاصلهى حــاقل سـه روز بعـد از خـرم

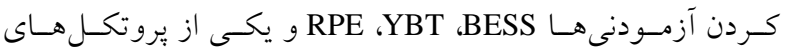
ورزشى را به صورت تصادفى انجام دادند. ســس بلافاصسله بعـد از

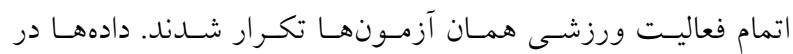
بركههاى ويزه هر آزمودنى ثبت شد. كرم كـردن شـامل يـنج دقيقـهـ

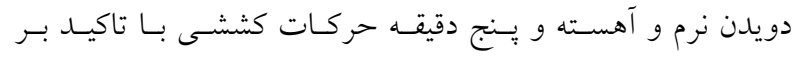

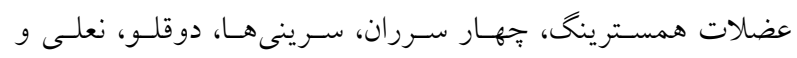
فلكسورهاى ران بود.

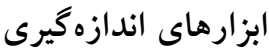

آزمون كانكانى با استفاده از تردميل

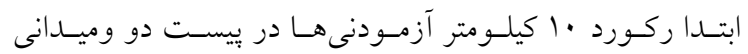

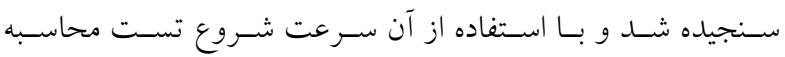
كرديد. بَّبس در جلسه بعدى آزمودنى ها بعد از گرم كردن، آزمون را روى تردميـل (Mercury 4.0, H/P/Cosmed, Germany)

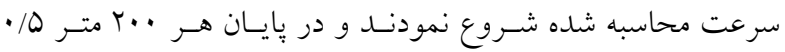
كيلومتر بر ساعت به سرعت اضافه مىشد و ضربان قلب و سـرعت

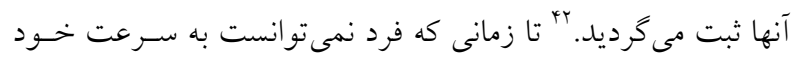

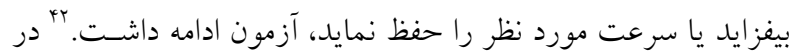

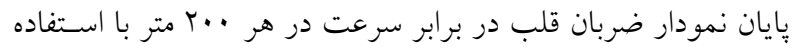

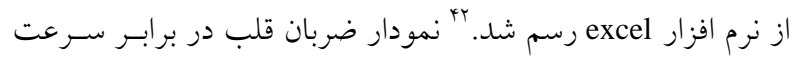
به صورت خطى بيش مىرود تا جايى كه به فلات رسيده و بعـد از آن نمودار به صورت غير خطى بيش مىرود،، جايى كـه نمـودار بـهـ

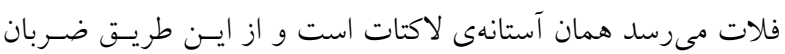
قلـب در آسـتانه لاكتـات (HRLT)

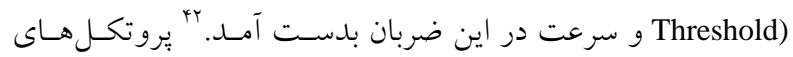

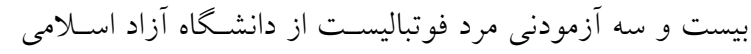
واحد كرج براى شركت در تحقيق داوطلب شــند كـه تمـامى آنهـا جهار جلسه در هفته، حداقل بـه مــدت •9 دقيقـه فعاليـت داشـتند.

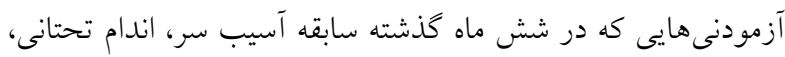

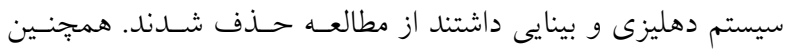
شركت كنــد كانى كـه در طـول سـه مـاه قبـل از انجـام تحقيـق در

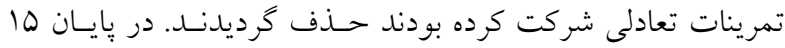

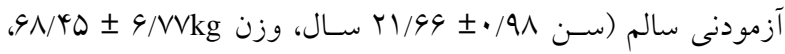
قد

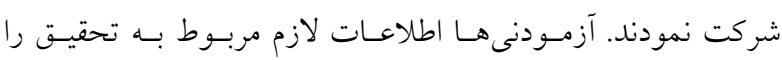

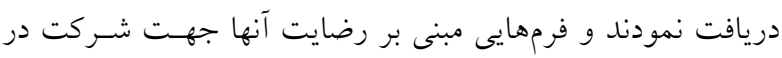

$$
\text { تحقيق امضا نمودند. }
$$

\section{روند انجام تحقيق}

آزمودنىها · ل ا جلسه در روزهاى غير متوالى به آزمايشگاه مركز

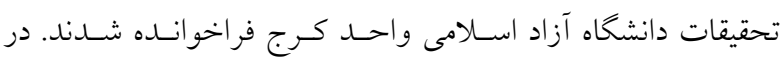

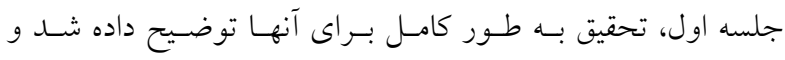

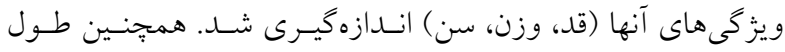
واقعى با از خار خاصرهى فوقانى قدامى لكن تا قوزى داخلى جهت

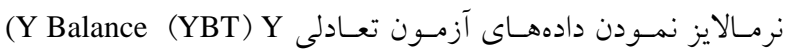

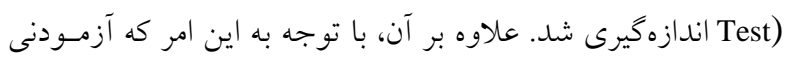

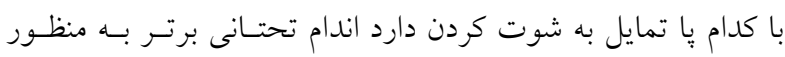
انجام آزمونهاى تعـادل تعيسين گرديــ. در جلسـه دوم، ركـورد . كيلومتر آزمودنىها در يِيست دو و ميدانى ثبت شد. در جلسه سـوم،

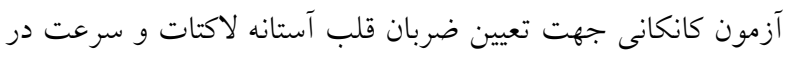

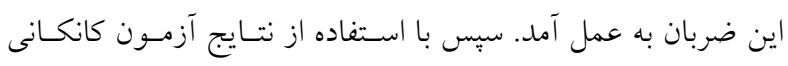

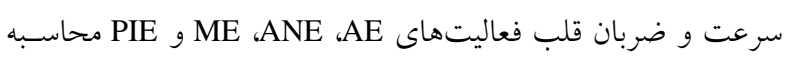
كرديد. در جلسه جهارم ركـورد دوى سـرعت در مسـير •4 متـرى

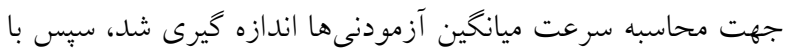


براى محاسبه اين مسافت از فرمول سرعت برابر است بـا جابجـايى

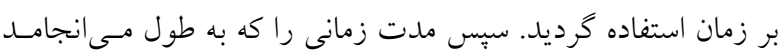
تا آزمودنى مسافت محاسبه شده را با سرعت يُووتكل هـوازى طـى نمايد طريق همان فرمول سرعت محاسبه شد. يـس از گــرم كـردن، آزمودنى با سرعت يروتكل هوازى و به مدت حدود بع ثانيه (همان زمان محاسبه شده براى طى مسافت تعيين شده با سرعت هوازى) و

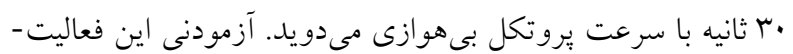
هاى VY ثانيهاى را بدون استراحت و به طور متوالى انجام مى داد تـا

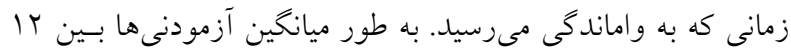
تا 19 وهله Y V دو ثانيهاى تركيبى را انجام دادند (جدول (1).

\section{تناوبى بلند مدت}

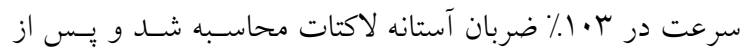

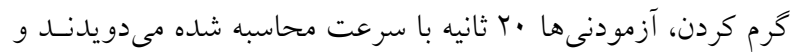
• † ثانيه به صورت غير فعال استراحت داشتند. اين وهله فعاليتهـا و استراحتهاى ·r ثانيهاى به مدت ·r دقيقه ادامه يافت (جدول ().
كوناگون ورزشى بر اساس درصدى از HRLT و سرعت دويــن در

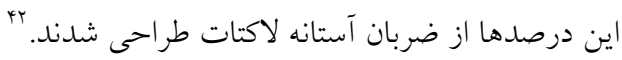

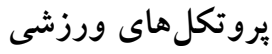

هوازى

ابتدا سرعت در ها ضربان پِايين تر از HRLT (آستانه هـوازى) با استفاده از نمودار ضربان قلب- سرعت براى هر آزمودنى محاسبه كرديد. بعد از كرم كردن در مـــت سـه دقيقـه سـرعت تردميـل بــه سرعت محاسبه شده در آستانه هوازى تغيير مىيافت و تا زمانى كـه

آزمودنى به واماندگى مىرسيد بروتكل را ادامه مى داد (جدول (1).

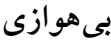
سرعت در •11/\% ضربان قلب آستانه لاكتات محاسبه شد و بعد از كرم كردن آزمودنى جند بار با سرعتهاى دلخــواه روى تردميـل مىدويد و سبس با سرعت محاسبه شده براى فعاليت بىهـوازى تـا سرحد و اماندگى مىدويد (جدول ()). تركيبى هوازى و بىهوازى: ابتدا مسافت طـى شـده در مـــت

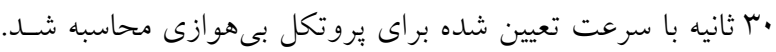

جدول ا: اطلاعات مربوط به يروتكلهاى ورزشى را نشان مىدهد

\begin{tabular}{|c|c|c|c|}
\hline ميانخين و انحراف استاندارد & 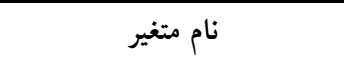 & ميانگين و انحر اف استاندارد & 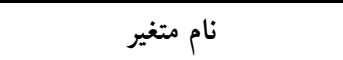 \\
\hline$r V \psi / l \cdot \pm r V / \cdot V$ & TS110\%HRLT (s) & $r / / 90 \pm r / \cdot V$ & 10 km (min) \\
\hline$I V A / M T \pm Q / T Y$ & 103\%HRLT (Beat.Min ${ }^{-1}$ ) & $199 / \cdot V \pm Y / 19$ & HRLT (Beat.Min ${ }^{-1}$ ) \\
\hline $11 / 0 V \pm 1 / 10$ & S103\% HRLT (Km/h) & $11 / r \wedge \pm 1 / 1 V$ & SHRLT (km/h) \\
\hline$\Lambda / \mu \cdot \pm \cdot / \mu \cdot$ & $60 \mathrm{~m}(\mathrm{~s})$ & $\mid Q \psi / \cdot V \pm \psi / \wedge q$ & HRAT (Beat.Min ${ }^{-1}$ ) \\
\hline$r Q / V T \pm \cdot / 9 r$ & AS $(\mathrm{Km} / \mathrm{h})$ & $q / 1 \uparrow \pm 1 / \cdot v$ & SHRAT (km/h) \\
\hline $1 \cdot 9 / \pi \cdot \pm 11 / \cdot 0$ & 30sD (m) & $V Q / \Lambda T \pm V / r G$ & TSHRAT (min) \\
\hline \multirow[t]{2}{*}{$41 / 9 V \pm \cdot / 19$} & PTPC (s) & $\mid \Lambda \Delta / \uparrow \Lambda \pm Q / 4 \varphi$ & 110\% HRLT (Beat.Min ${ }^{-1}$ ) \\
\hline & & IT/VG $\pm 1 / T \Delta$ & S110\%HRLT (km/h) \\
\hline
\end{tabular}

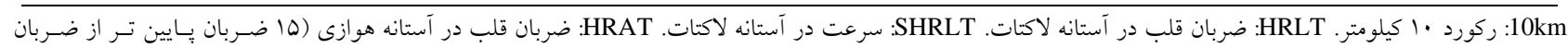

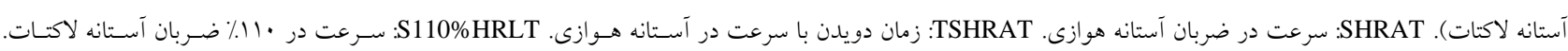

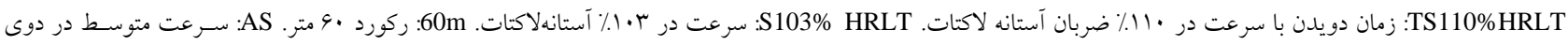

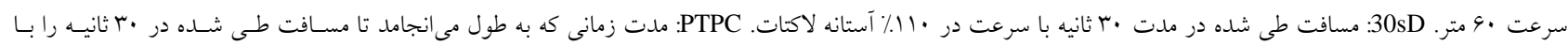
سرعت در ضربان آستانه هوازى طى نمايند. 


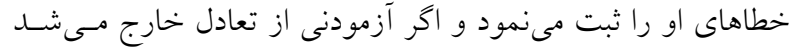

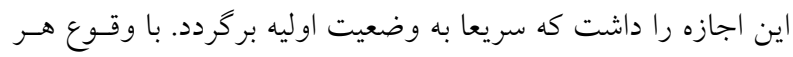

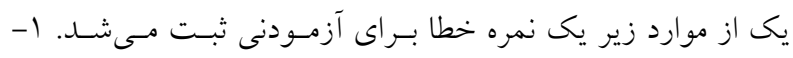

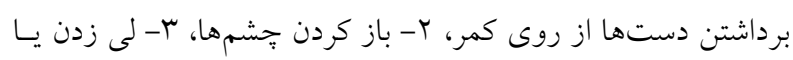

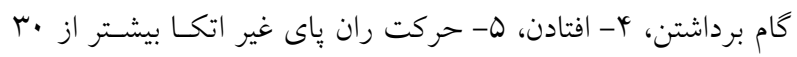
درجه فلكشن و ابداكشن در SLS، و- جدا شدن بِنجه بِاى غير برتر

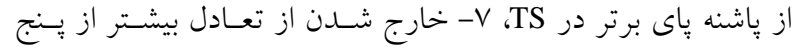

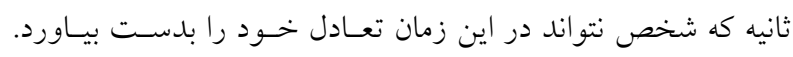

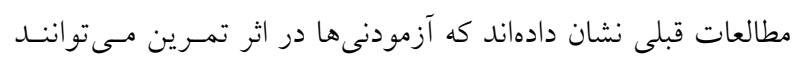

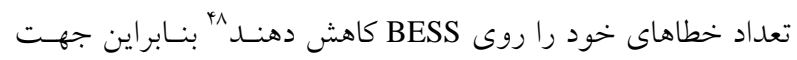

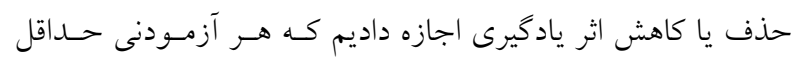

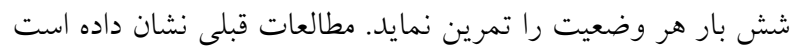

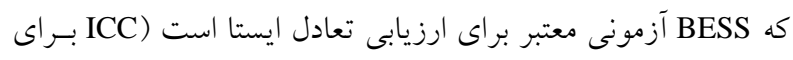

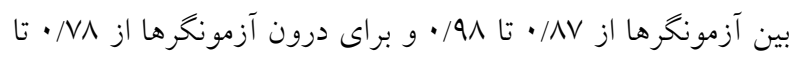

\section{آزمون تعادلى}

به منظور ارزيابى تعادل يويـا از Y Balance Test"TM) YBT در

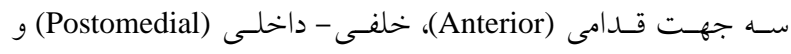

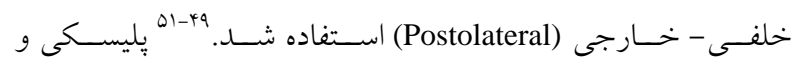

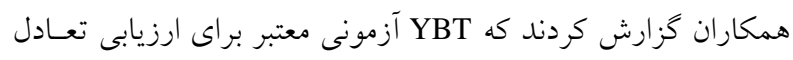

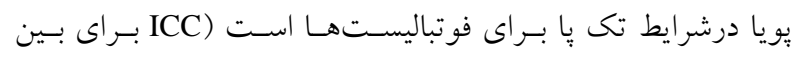

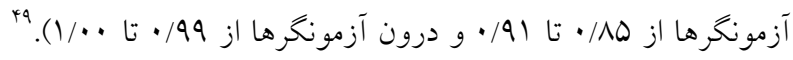

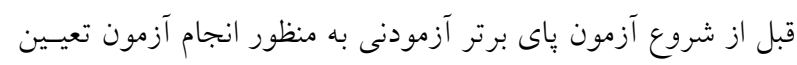

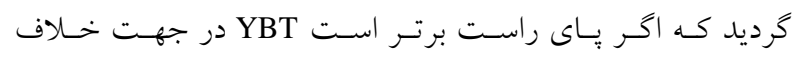

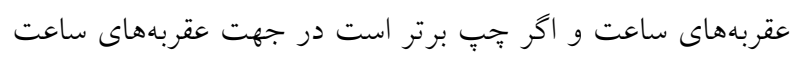

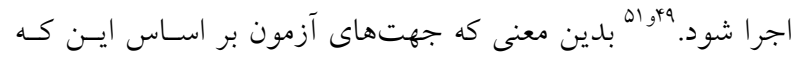

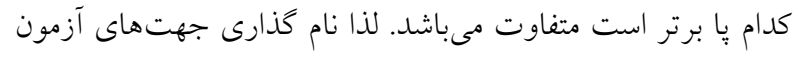

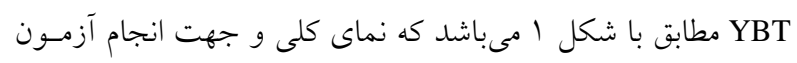

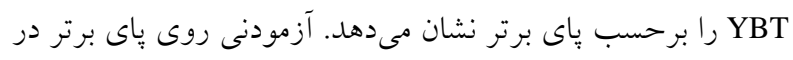

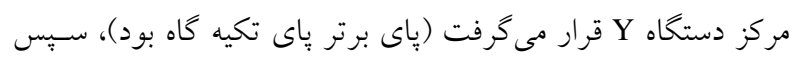

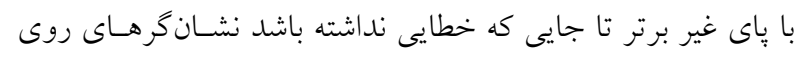
جهتهاى YBT را با انخشت شست پِإ حركت مى داد و دوبـاره بـهـ
فعاليت فوق بيشينه تناوبى

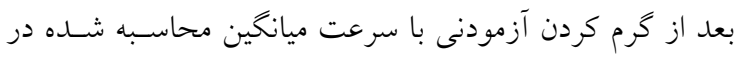

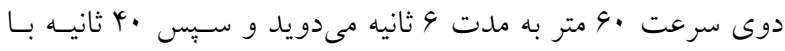

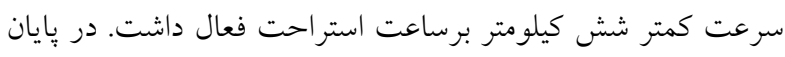

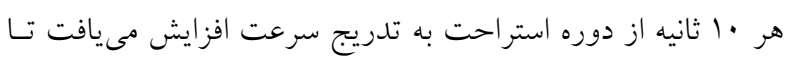

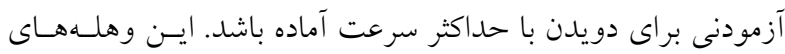

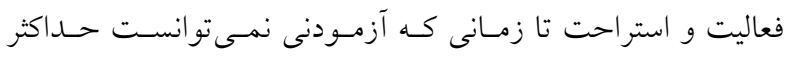

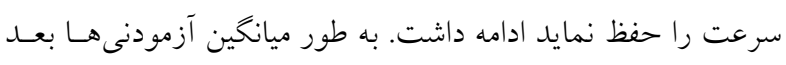

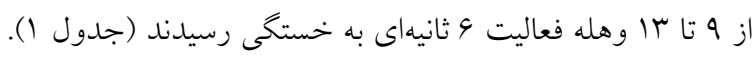

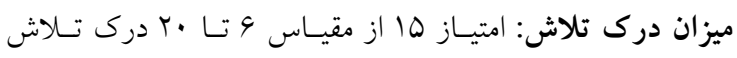
بورگ براى محاسبه RPE و اطمينان از اين كـه فعاليـتهـاى انجـام

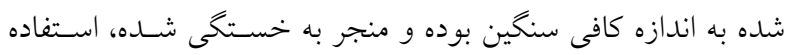

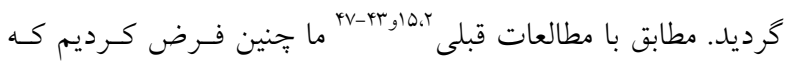

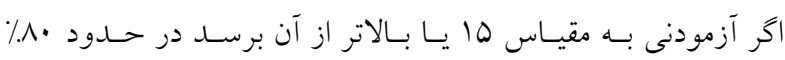

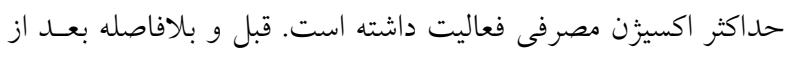
يروتكل هاى ورزشى RPE ارزيابى شد.

سيستم امتيازدهى خطاى تعادل

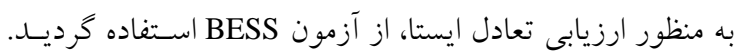

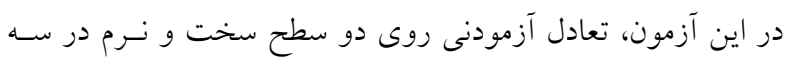

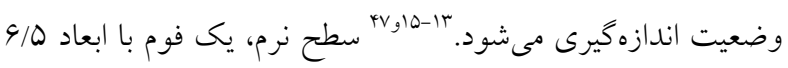

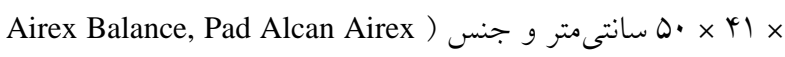
وضعت (AG, Sins, Switzerland وضعيت شامل دو پـا كنـار هـم و جسـبيده (Double Leg (DLS) (Single-leg Stance)(SLS) و دو پـاـا

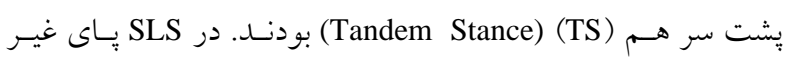

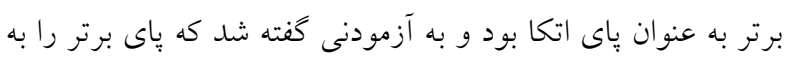

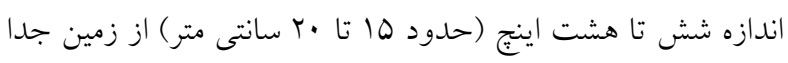

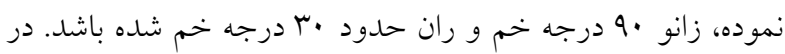

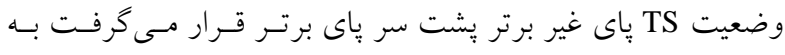

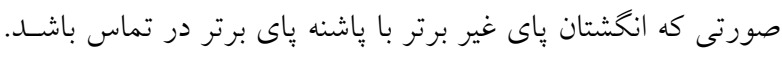

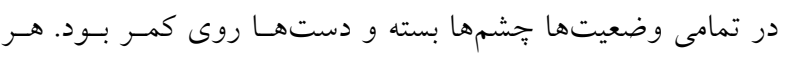

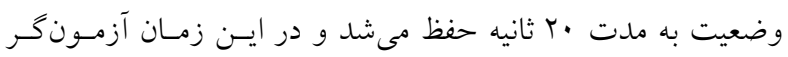


وضعيت و سطح) به منظور بررسى عملكرد روى BESS در شـر ايط

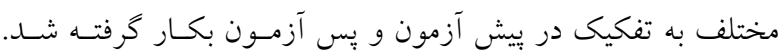

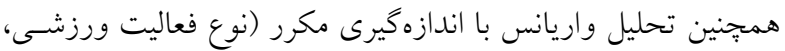
زمان و وضعيت) جهت بررسى اثر خستخى بـر شـر ايط كونـاكون

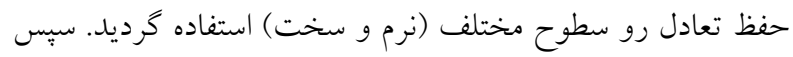

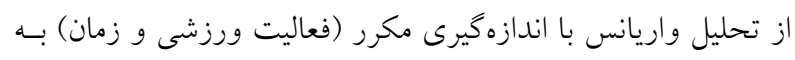
تفكيك براى هر كدام از وضعيتهاى حفظ تعادل روى سطوح نـرم و سخت جهت بررسىهاى بيشتر و تعيين اختلافات بين فعاليت هـا

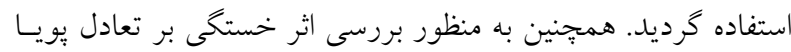

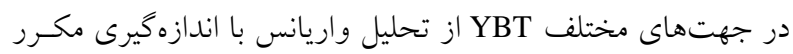

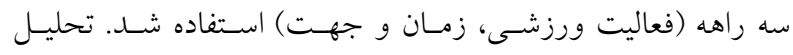

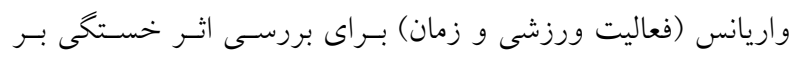
جهتهاى YBT اعمال گرديد. در نهايت براى تعيسين تفـاوتهـاى وراى بين فعاليت هاى ورزشى در بّ آزمون از تحليل واريانس يك راهـ

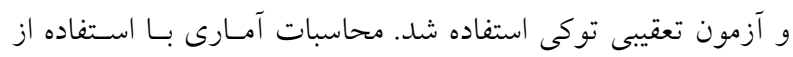

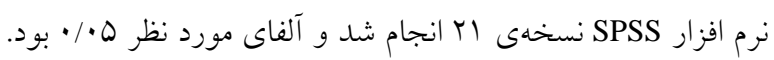

يافته ها

اثر هر كدام از فعاليتها بر RPE

نتايج تحليل واريانس با اندازهكيرى مكرر تعامل معنىدارى بـين

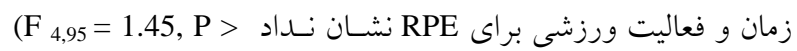

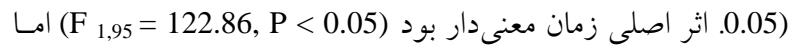
اين اثر براى فعاليت ورزشى معنىدار نبود (F)

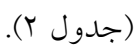

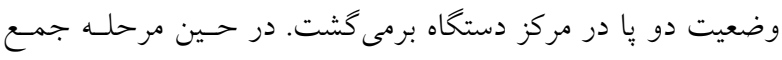

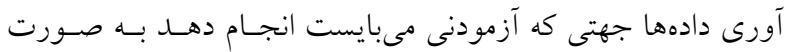

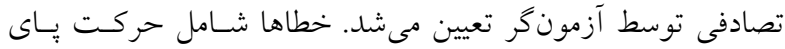

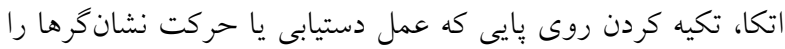

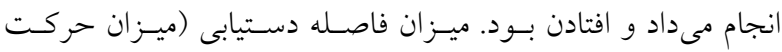
نشانكرها) بر حسب سانتى متر محاسبه شد و در يايان براى از بـين

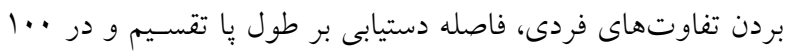

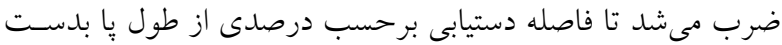

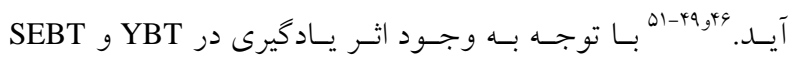

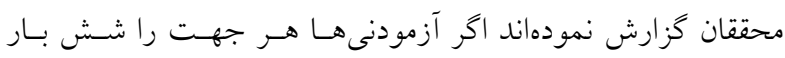

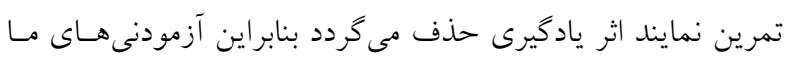

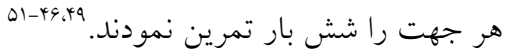

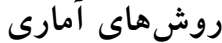

بـراى توصسيف دادههـا از آمـار توصسيفى ميـانگين و انحـراف استاندارد استفاده شد. به منظور بررسى دادههاى مربــوط بــه RPE از از

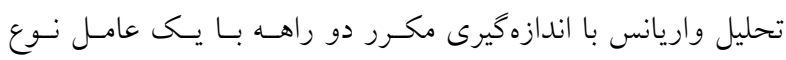

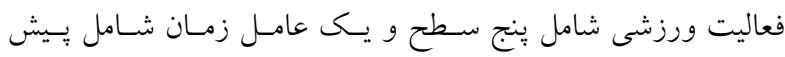
آزمون و پِس آزمون استفاده كرديد. براى تجزيه و تحليـل عملكـرد

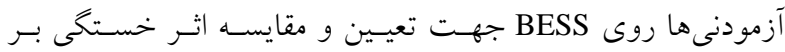

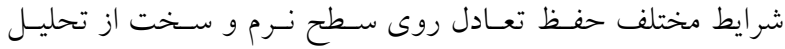

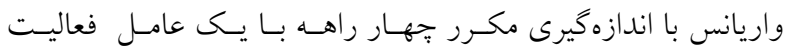

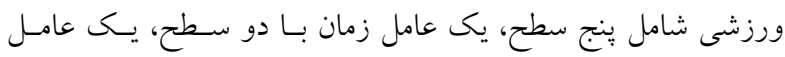

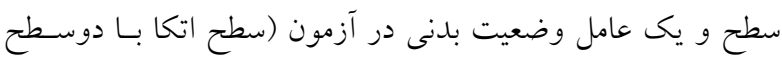

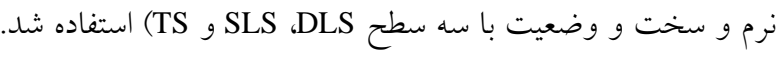

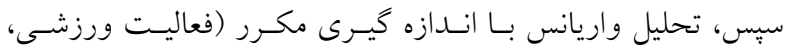

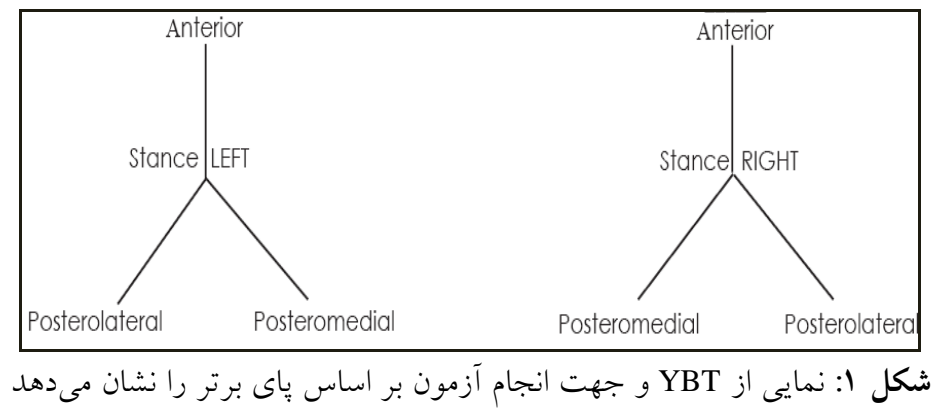


جدول Y: دادههاى توصيفى و نتايج آزمونهاى تعقيبى RPE را نشان مىدهد.

\begin{tabular}{|c|c|c|c|c|c|}
\hline SMIE & PIE & ME & ANE & $\mathbf{A E}$ & آزمون \\
\hline $9 / 99 \pm \cdot / V Y$ & $q / r V \pm \cdot / 09$ & $9 / 00 \pm \cdot / 90$ & $9 / V Q \pm \cdot / 0$. & $G / \mu Y \pm \cdot / \mu V$ & ييش آزمون \\
\hline$|\Lambda / r| \pm \cdot / r q^{*}$ & $|V / q| \pm \cdot / V q^{*}$ & $11 / \cdot 9 \pm \cdot / 9 V^{*}$ & $|N /| T \pm \cdot / V \varphi^{*}$ & $I V / \Lambda D \pm \cdot / \Lambda Y^{*}$ & يس آزمون \\
\hline
\end{tabular}

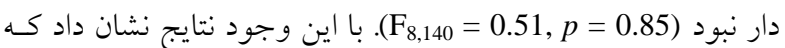
در يس آزمون تعداد خطاها در DLS، SLS و TS روى سطح نرم به

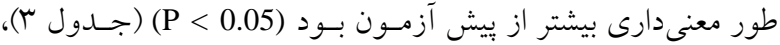
همجنين تعداد خطاها در بين فعاليتهاى ورزشى متفاوت بود > p ( )

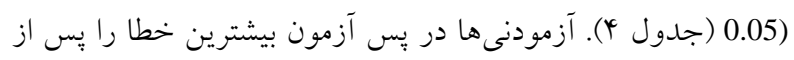

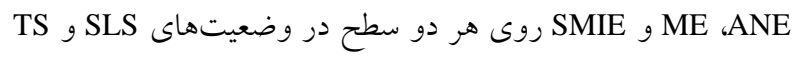

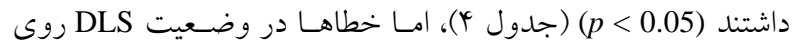
نرم در يس آزمون بين فعاليتهاى ورزشى اختلافى نداشتند، با ايسن

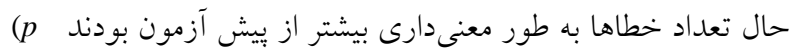
(ج) (جدول) تعامل سه متغير فعاليت ورزشى × سـطح × وضـعيت در يسيش آزمون BESS معنى دار نبود (F,140 دادهها نشان داد كه حتى در بيش آزمون، مجموع كل خطاها در سـه وضعيت روى سطح نرم (1.44 × 9.27 = تعداد كل خطاهـا) نسـبت به سطح سخت (1.20 × 5.05 = تعداد كل خطاها) بيشتر بوده اسـت (0.05) 0.05$)$

$$
\text { بيشتر از سطح سخت بود (0.05 > p). }
$$

اثر فعاليت بر عملكرد BESS يافتهها نشان داد كه تعامل ججهار عامل فعاليت ورزشسى ، زمـان، وضعيت و سطح براى BESS معنسى دار نيست = (0.93. همجِنين نتايج نشان داد كه تعامل نتايج براى تعامـل فعاليـت

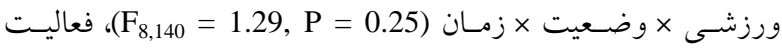
ورزشى × زمان × سطح (F,70 = 0.2, P = 0.72) و فعاليت ورزشى (F) × وضعيت × سـطح $)$ (F,140 = 0.49, P = 0.86) معنسى دار نبـود. امـا تعامل زمان × وضعيت × سطح $\left(\mathrm{F}_{2,140}=17.24, p\right.$ معنى دار بود. نتايج تعامل معنى دار فعاليت ورزشى × زمان × وضعيت را روى

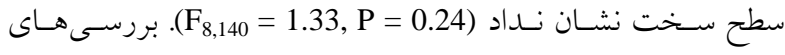
بيشتر نشان داد كه در DLS روى سطح سخت اختلافى بسين تعـداد

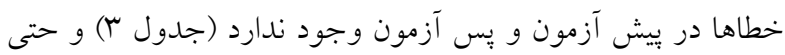
در يس آزمون نيز اختلافى بين فعاليتهاى ورزشسى از نظـر تعـداد خطاها وجود ندارد (0.05 > p) (جدول ץ). اما عملكرد گـروههـا در TS ورى سطح سخت به طور معنى دارى متفــاوت از يـيش SLS آزمون بوده (جدول ؟) و در يس آزمون اختلافــات معنسى دارى بـين فعاليتهاى ورزشى وجود داشت (جدول أ). تعامل فعاليت ورزشى × زمان × وضعيت روى سطح نرم معنى -

جدول س: دادههاى توصيفى و نتايج آزمونهاى تعقيبى مربوط به عملكرد تعادلى روى BESS را برحسب تعداد خطاهـا بـدون توجـهـ بـه فعاليـت ورزشى كه آزمودنى ها در آن قرار دارند نشان مىدهد

\begin{tabular}{|c|c|c|c|c|}
\hline \multicolumn{2}{|c|}{ سطح نرم } & \multicolumn{2}{|c|}{ سطح سخت } & \\
\hline يس پ آزمون & بيش آزمون & 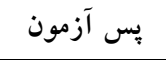 & بيش آزمون & \\
\hline & & & & وضعيت حفظ تعادل \\
\hline$r / 99 \pm 1 / \Gamma 1$ & $r / N \pm \cdot / V q$ & $1 / r \cdot \pm \cdot / \Lambda r$ & $1 / 11 \pm \cdot / 91$ & دو يا كنار هم (DLS) \\
\hline$\Delta / 94 \pm 1 / \cdot r$ & $\Gamma / \wedge \Delta \pm \cdot / 91$ & $r / 9 r \pm 1 / 1$. & T/YYE $\pm / / \Lambda$ & ايستادن روى يك پا (SLS) \\
\hline $4 / 94 \pm 1 / 19$ & $\Gamma / \Gamma \Lambda \pm \cdot / 9 V$ & $\Gamma / / V \pm \cdot / \Lambda \varphi$ & $1 / N T \pm \cdot / 01$ & دو پِا در يك خط (TS) \\
\hline
\end{tabular}


جدول \&: دادهاى توصيفى و آزمونهاى تعقيبى مربوط به عملكرد روى BESS بر اساس تعداد خطاها را به تفكيك در وضسعيتهـاى كونـاكون،

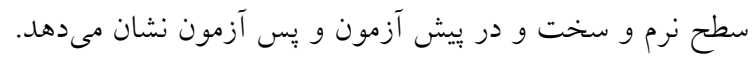

\begin{tabular}{|c|c|c|c|c|c|}
\hline \multicolumn{6}{|c|}{ بروت تكله هاى خستى } \\
\hline ANOVA يك راهه براى وضعيت در ييش & SMIE & PIE & ME & ANE & $\mathbf{A E}$ \\
\hline و يس آزمون & & & & & \\
\hline
\end{tabular}

\begin{tabular}{|c|c|c|c|c|c|c|c|}
\hline & & & & & & سطح و زمان & وضعيت \\
\hline & & & & & & سخت & DLS \\
\hline 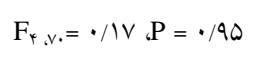 & $1 / \cdots \pm \cdot / v 9$ & $1 / 14 \pm \cdot / N 4$ & $1 / T \cdot \pm \cdot / 9 \Lambda$ & $1 / 1 r \pm \cdot / 94$ & $1 / \cdot v \pm \cdot / v$ & يبش & \\
\hline \multirow[t]{2}{*}{ 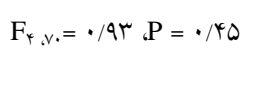 } & $1 / N T \pm \cdot / \Lambda T$ & $\cdot / 9 r \pm \cdot / \wedge$ & $1 / / 4 \pm \cdot / V 4$ & $1 / 49 \pm \cdot / V^{4}$ & $1 / 1 r \pm \cdot / 99$ & 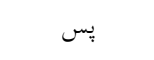 & \\
\hline & & & & & & 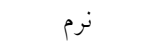 & \\
\hline$F_{4, v}=\cdot / 11 ، \mathrm{P}=\cdot / 9 \Lambda$ & $r / \cdot V \pm \cdot / A r$ & $r / r \cdot \pm \cdot / N V$ & $r / T \cdot \pm \cdot / \Lambda q$ & $r / / r \pm \cdot / 94$ & $r / / r \pm \cdot / 9 r$ & ييش & \\
\hline \multirow{2}{*}{$\mathrm{F}_{\psi_{t, v} \cdot}=\cdot / 91 ، \mathrm{P}=\cdot / 90$} & $r / 9 \cdot \pm 1 / r^{a}$ & $r / 9 V \pm 1 / 4 \theta^{a}$ & $r / / r \pm 1 / 19^{a}$ & $r / q V \pm 1 / r q^{a}$ & $r / \kappa \cdot \pm 1 / \kappa \omega^{a}$ & 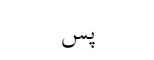 & \\
\hline & & & & & & سخت & SLS \\
\hline$F_{\psi, V}=\cdot / Y Y_{1} \mathrm{P}=\cdot / 91$ & $r / r \cdot \pm \cdot / \Lambda 9$ & $r / T V \pm \cdot / \Delta 9$ & $r / r \pm 1 / 1 r$ & $r / 4 \cdot \pm \cdot / \Lambda r$ & $r / 1 r \pm \cdot / 91$ & يِي & \\
\hline \multirow[t]{2}{*}{$F_{\psi, v}=\Lambda / r V ، P<\cdot / \cdot 0^{*}$} & $c / 4 \cdot \pm \cdot / N r^{a}$ & $r / v \pm \cdot / v \cdot a g$ & $r / \psi \cdot \pm 1 / r \Delta^{\text {af }}$ & $r / 4 v \pm 1 / \cdot 9^{\mathrm{ae}}$ & $r / T V \pm 1 / \Delta q^{\text {abcd }}$ & يس & \\
\hline & & & & & & 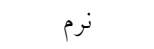 & \\
\hline$F_{\psi, v}=\cdot / 99, P=\cdot / 9$. & $r / N \pm \cdot \cdot \wedge$ & $r / \Lambda \cdot \pm \cdot / \Lambda \varphi$ & $r / \Lambda \cdot \pm \cdot / N V$ & $r / r \cdot \pm \cdot / 9 r$ & $r / N \pm \pm 1 / 9$ & ييش & \\
\hline \multirow[t]{2}{*}{$F_{\psi, v}=\Delta / \Delta \Delta, P<\cdot / \cdot Q^{*}$} & $9 / 1 r \pm 1 / 1 r^{\mathrm{a}}$ & $\Delta / \cdot \cdot \pm \cdot / \wedge Q^{\mathrm{ag}}$ & $9 / \cdot \cdots \pm \cdot / 9 Y^{\text {af }}$ & $q / \cdot \cdot \pm \cdot / v^{a e}$ & $\Delta / \cdot \vee \pm \cdot / \Lambda \Lambda^{\mathrm{abcd}}$ & 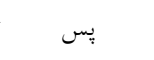 & \\
\hline & & & & & & سخت & TS \\
\hline$F_{*, V}=\cdot / / V, P=\cdot / 9 D$ & $1 / 99 \pm \cdot / 49$ & $1 / N r \pm \cdot / 44$ & $1 / 9 V \pm \cdot / 49$ & $1 / N \pi \pm \cdot / \Delta 9$ & $1 / 1 \cdot \pm \cdot / 09$ & 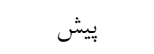 & \\
\hline \multirow[t]{2}{*}{$F_{Y, V}=V / \Delta{ }^{Y}, P<\cdot / \cdot Q^{*}$} & $r / 9 \cdot \pm \cdot / q \mu^{a}$ & $r / 9 \cdot \pm \cdot / 9)^{\text {ag }}$ & $r / \Delta r \pm \cdot / 9 r^{a f}$ & $r / \Delta f \pm \cdot / q c^{a e}$ & $r / 9 \cdot \pm \cdot /\left.\Delta\right|^{\mathrm{abcd}}$ & يس & \\
\hline & & & & & & 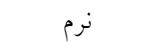 & \\
\hline$F_{4, v \cdot}=1 / 19, P=\cdot / r 4$ & $r / 4 \cdot \pm \cdot / 01$ & $r / 4 V \pm \cdot / q \varphi$ & $r / r \cdot \pm \cdot / N V$ & $r / r r \pm \cdot / 9 r$ & $r / \cdots \pm \cdot / v q$ & بيش & \\
\hline$F_{\psi_{\Delta}, \cdot}=r / 9 r, P<\cdot / \cdot 0^{*}$ & $r / \Lambda \cdot \pm|/ r|^{a}$ & $r / q V \pm \cdot / q r^{a}$ & $\Delta / \cdot \pm|/| \times\left.\right|^{a}$ & $0 / 1 r \pm 1 / \cdot 9^{\mathrm{a}}$ & $\Gamma / \Lambda \cdot \pm \cdot / 9 \Lambda^{\mathrm{abcd}}$ & 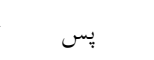 & \\
\hline
\end{tabular}

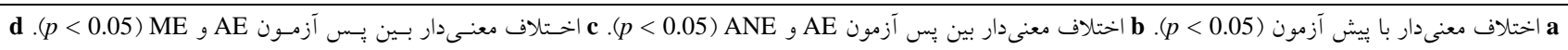

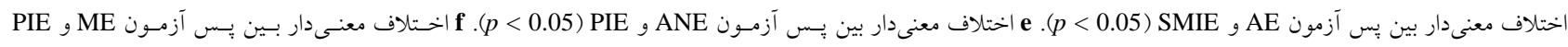

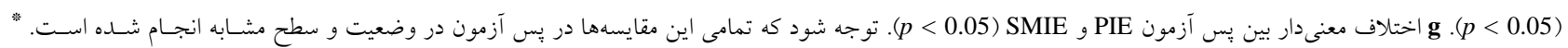
اختلاف معنى دار (p0.05)

داد كه بعد از خستخى، تعادل ايستا روى سـطح نـرم (2.30 ـ 13.97

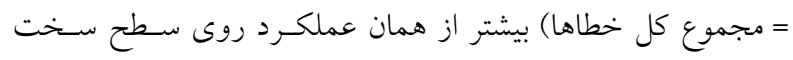

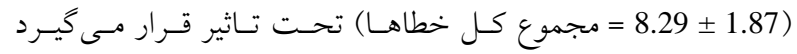

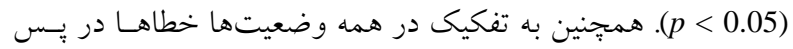

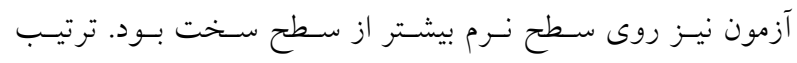
وضعيتها در ييش آزمون بر حسب تعداد خطاها روى سطح سخت و SLS (3.92 \pm 1.10$)>$ TS $(3.17 \pm 0.86)>$ DLS (1.20 \pm 0.83$)$ SLS $(5.64 \pm 1.02)>$ TS $(4.64 \pm 1.16)>$ DLS روى سـطح نـرم

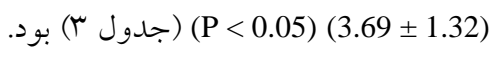

ترتيب وضعيتها در بيش آزمون بر حسب تعداد خطاهـا روى

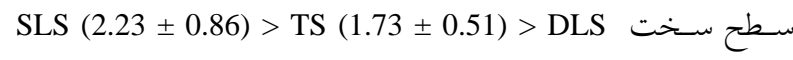

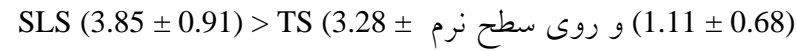

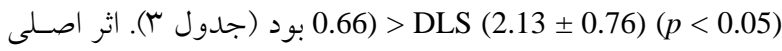
(F,70 = 0.86, P = فعاليت ورزشى در بيش آزمسون معنسى دار نبـود

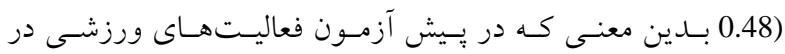
وضعيتهاى مخلتف اما سطح مشابه اختلاف معنىدارى نداشتند. تعامل سه متغير فعاليت ورزشسى × سـطح × وضسعيت در يسس

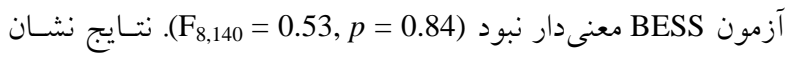


ANE (17.88\%) > ورزشى بر اساس درصد كاهش در جهت قدامى $\operatorname{SMIE}(17.34 \%)>\operatorname{ME}(14.86 \%)>\operatorname{PIE}(10.75 \%)>\mathrm{AE}$ ANE (14.45\%) > SMIE (11.40\%) > (6.25\%)، خلفسى - داخلى > (10) - ME (10.72\%) > PIE (4.07\%) > AE (2.74\%) ANE (16.06\%) > SMIE (15.20\%) > ME (13.44\%) > خـارجى PIE (8.84\%) > AE (5.69\%)

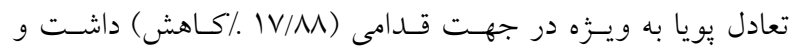

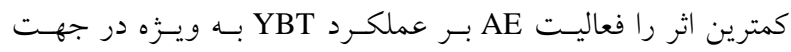

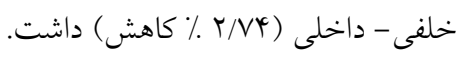

اثر فعاليت بر عملكرد روى YBT

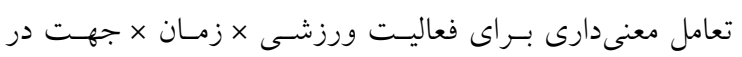

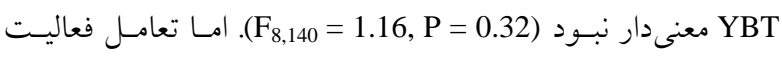
ورزشى ×زمان و تحليل واريانس يكى راهه بـــاى بـس آزمـون بـهـ تفكيك براى تمامى جهت ها معنى دار بود (جدول ه).

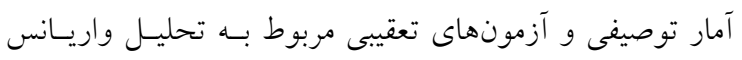

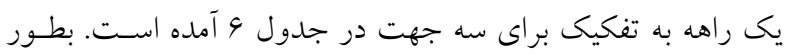

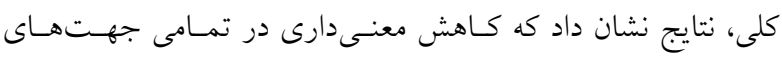
YBT

جدول ه: خلاصهاى از نتايج آمارى تحليل واريانس به تفكيك براى هر كدام از جهتهاى YBT.

\begin{tabular}{|c|c|c|c|c|}
\hline تحليل واريانس يك راهه از جهتها & اثر اصلى فعاليت ورزشى & اثر اصلى زمان & تعامل فعاليت ورزشى و زمان & \\
\hline$F_{\psi, v}=1 \% / \Delta V ، P<\cdot / \cdot 0^{*}$ & $F_{\psi, v}=V / \cdot, P<\cdot / \cdot 0^{*}$ & 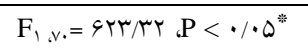 & $F_{\psi}, v=19 / 44, P<\cdot / \cdot 0^{*}$ & 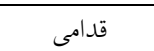 \\
\hline$F_{*, v}=r r / \Delta V, P<\cdot / \cdot \Delta^{*}$ & $F_{\psi, v}=\Delta / r q, P<\cdot / \cdot \Delta^{*}$ & $F_{1, v \cdot}=11 r q / r \cdot d \mathrm{P}<\cdot / \cdot \Delta^{* *}$ & $F_{*, v}=V V / 19, P<\cdot / \cdot 0^{*}$ & 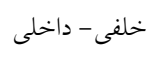 \\
\hline$F_{\psi, v}=I V / q V ، P<\cdot / \cdot D^{* *}$ & $F_{\psi, V}=\Delta / I V, P<\cdot / \cdot Q^{*}$ & $\mathrm{~F}_{1, v \cdot}=11 \cdot 1 / r \cdot{ }_{d} \mathrm{P}<\cdot / \cdot 0^{* *}$ & $F_{\psi, v}=r \cdot / \Lambda r, P<\cdot / \cdot Q^{*}$ & خلفى - خارجى \\
\hline
\end{tabular}

جدول و: آمار توصيفى و نتايج آزمونهاى تعقيبى براى فاصلهى دستيابى (برحسب درصدى از طول يّ) در سه جهت YBT.

\begin{tabular}{|c|c|c|c|c|c|}
\hline \multicolumn{6}{|c|}{ بروتكل هاى خستخى } \\
\hline SMIE & PIE & ME & ANE & AE & \\
\hline & & & & & جهت، زمان \\
\hline $1 \cdot r / 1 r \pm r / l r$ & $1 . r / 9 r \pm 0 / 19$ & $1.1 / r q \pm r / r$. & $1 \cdot r / 1 \cdot \pm r / 9 \cdot$ & l.r/Ar $\pm r / 9 q$ & ييش آزمون \\
\hline$|\psi / 4| \pm q / r^{\mathrm{a}}$ & $91 / 09 \pm r / 9 r^{\mathrm{ag}}$ & $\Lambda \varphi / r r \pm \Delta / 9 \Delta^{\text {af }}$ & $\Lambda r / \Lambda Y^{\mathcal{L}} \pm \Delta / \mathcal{Y q}^{\mathrm{ae}}$ & 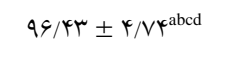 & پِ آزمون \\
\hline $1 r \cdot / \cdot 9 \pm 0 / \cdot 1$ & $|r \cdot / N| \pm r / N \Delta$ & $119 / v \cdot \pm r / 19$ & $|r| / \Delta \mid \pm Q / \Delta$ & $119 / \Gamma^{\circ} \pm \mathrm{r} / \mathrm{q}$. & ييش آزمون \\
\hline $1 \cdot 9 / r q \pm r / N 1^{a}$ & $110 / v 9 \pm F / N^{\mathrm{ag}}$ & $1.9 / 19 \pm r / 9)^{\text {af }}$ & $1 \cdot r / \Lambda Y \pm r / 9 \cdot$ ae & $119 / \cdot V \pm \Delta / \Delta r^{\mathrm{abcd}}$ & پِ آزمون \\
\hline$|r \cdot \kappa \wedge \pm \Delta / r|$ & Irq/N $\pm \Delta / 9 q$ & $\mid r q / q r \pm r / r q$ & $\mid r q / 4 \Delta \pm \Delta / / F$ & $\mid r q / \wedge q \pm \Delta / \cdot \Delta$ & بيش آزمون \\
\hline $11 \cdot / \Delta \Delta \pm r / 9 V^{a}$ & $\| N / T \Delta \pm \Delta / 1 \Delta^{\mathrm{ag}}$ & $\| r / r \cdot \pm \Delta / r q^{\text {af }}$ & $1 \cdot N / 90 \pm \psi / \Lambda r^{\mathrm{ae}}$ & $\mid r T / \| \pm \Delta / N$ rabcd & بس آزمون \\
\hline
\end{tabular}

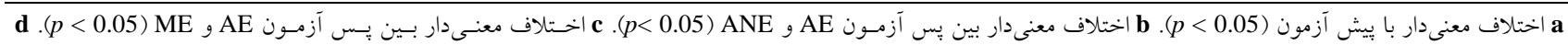

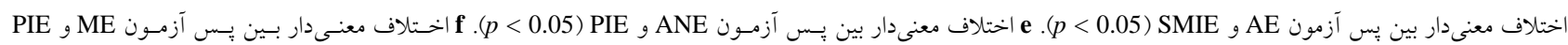

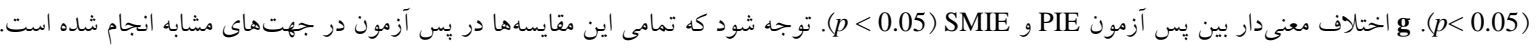


منجر به اختلال كنترل حركتى بيشترى نسبت به فعاليت AE كردد.

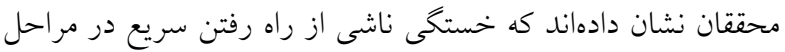

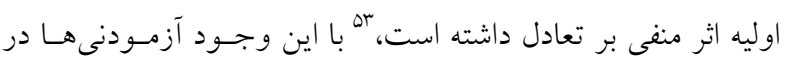
مر احل بعدى با افزايش حركات اصـلاح كنــدهى باسـحر توانستـند

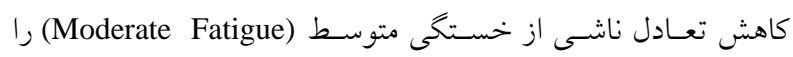

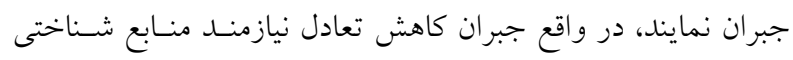
بيشترى جهت حفظ و كنترل فعال تعادل بود. هم همجنين، نشـان داده شده كه در اثر خستخى ممكن است مكانيزمهاى عصسبى - عضـانى

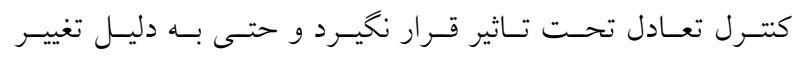

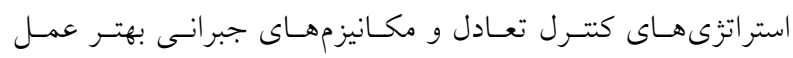

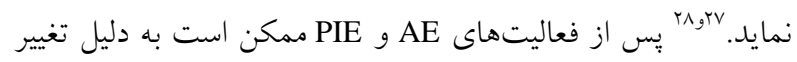
مكانيزمهاى كنترل تعادل در سيستم عصـبى مركسى كـاهش تعـادل كمترى نسبت به ديخر فعاليتها ايجاد شده است. بنابر اين، فعاليـتـهاى AE و PIE ممكن است منجر بـه خستخى عصسبى -عضلانى متوسطى شده و سيستم كنترل تعادل از مكانيسمهاى جبرانى استفاده

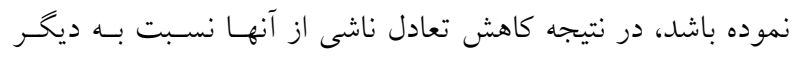

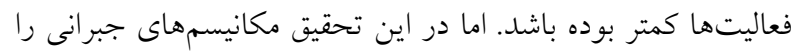
بررسى نشده است و لازم اسـت در تحقيقـات بعـدى فعاليـتهـاى

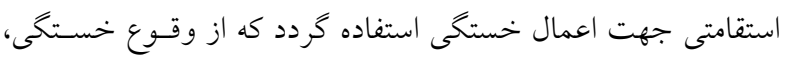
خصوصا خستكى مركزى اطمينان حاصل كردد.

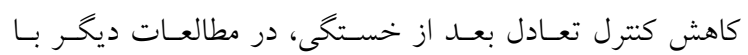
استفاده از روشهـاى كونـاكون اعمـال خستخّى و ارزيسابى تعـادل كزارش شده است. براى مثال فوكس و همكارانش تغييرات معنى دارى در عملكرد روى BESS و صفحه نيرو (Force Platform) بعد فيدات

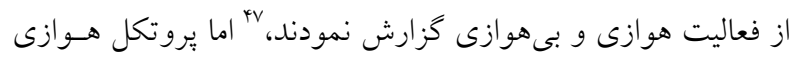

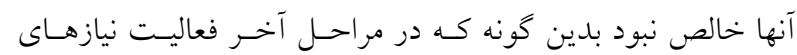

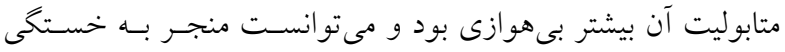

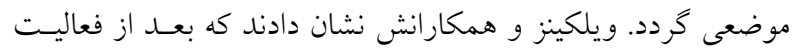

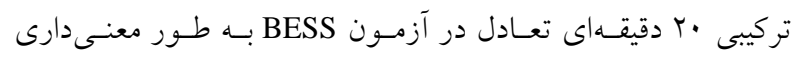

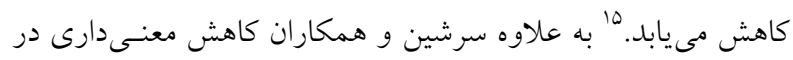
فاصلهى دستيابى در تمامى جهتهاى SEBT بعد از فعاليت تركيبى

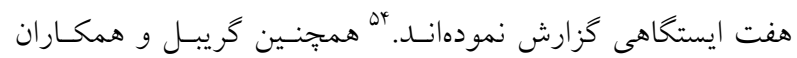

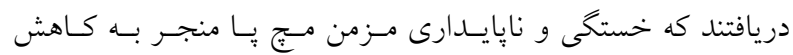

\section{بحث و نتيجه گيرى}

هدف از انجام تحقيق بررسى اثــ فعاليـت دويــن بـا شـــت و و مدتهاى كوناكون بر شرايط مختلف كنترل تعادل ايستا و يويا بـود.

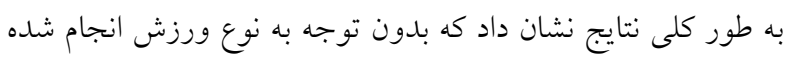

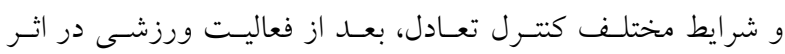
خستكى ناشى از آن تعادل كاهش مى يابد. اما بيشترين كاهش تعادل

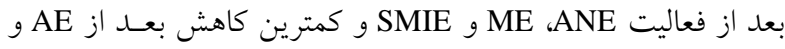

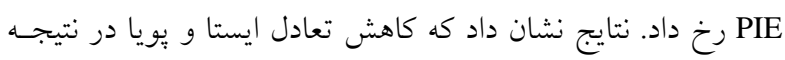

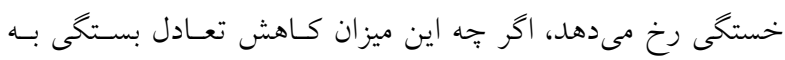

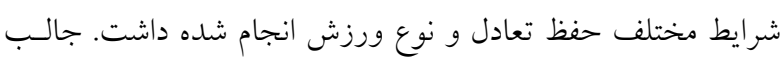
اين كه در هر دو آزمون BESS و YBT بيشترين ميزان كاهش تعادل

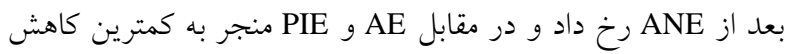
تعادل شدند. با اين وجـود اثـ ME و SMIE بـهـ طـور معنى داري

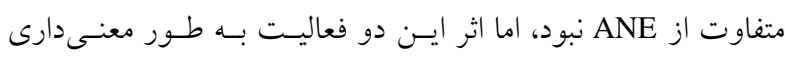

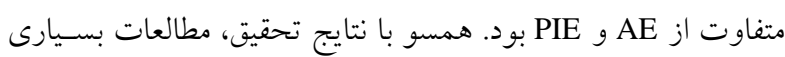

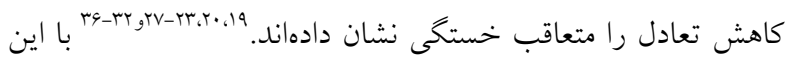
وجود در بسيارى از موارد نتايج اين كونه مطالعات به دليل استفاده

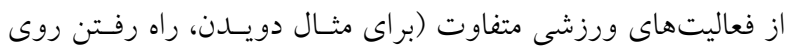

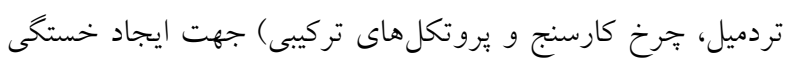
قابل مقايسه نيستند. فعاليت ورزشى كه به طور ناكهانى با شدت بالايى شـروع مسى - فئن

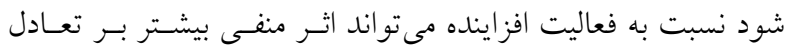

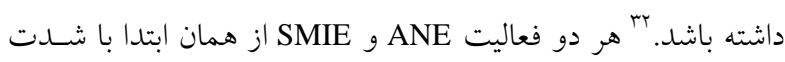

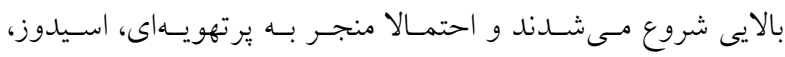

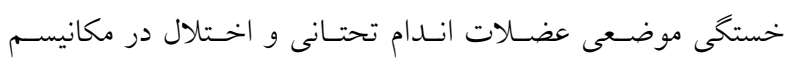

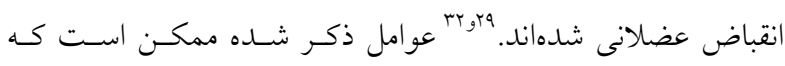
بخـش محيطى سيستم كنتـرل قامـت (Control Posture System) (بخش محيطى سيستم عصبى و عضلات) را مختل نمـوده باشـند و

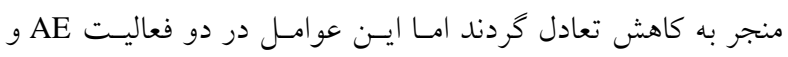

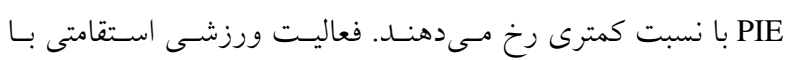

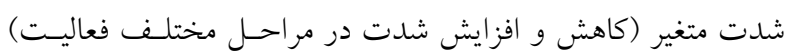

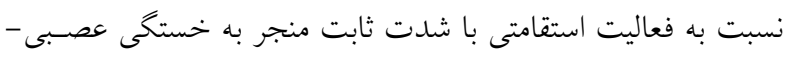

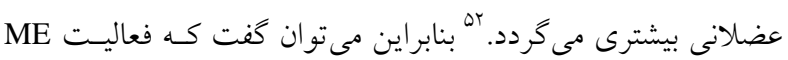


وضعيتها مشكلتر نموده است. بنابراين آزمودنىها در SLS نسبت

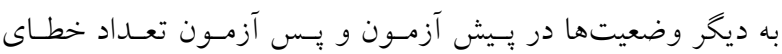
بيشترى داشتند، البته اين تعداد خطاى بيشتر روى سطح نرم بـارزتر

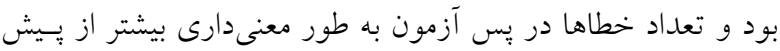

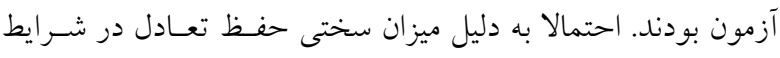
حتى اختلال كمى در سيستم كنترل ياسجر مى SLS كاهش زياد عملكرد تعادلى در اين وضعيت كردد. از آنجايى كه كنترل تعادل يويا مهارتى فعـال اسـت بـه منظـور

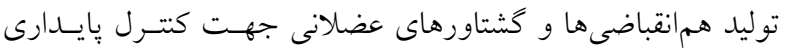
پِاى اتكا و حركت COP نسـبت بــه تعـادل ايسـتا نيازمنــ كنتـرل

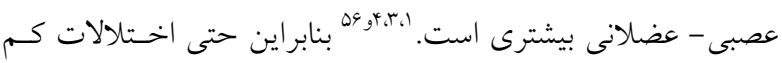

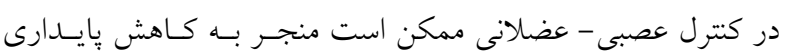
وضعيت بِاسجر و حركت فعال COP كردند. نتايج ما كاهش معنسى دارى در فاصله دستيابى در همه جهتهاى YBT نشان داد به ويـزّه ميزان كاهش در جهت قدامى بيشتر از جهتهاى ديخر بود كه جنين

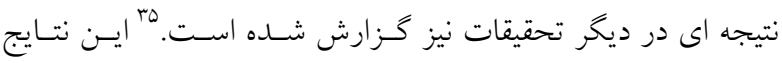

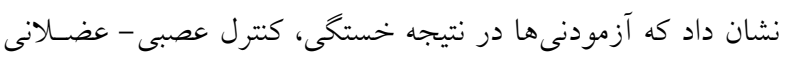
مناسبى جهت تثبيت پِاى اتكا را خصوصا در جهت قدامى نداشته و نتو انستند به عملكردى در سطح بيش آزمون داشته باشـــد. محققـان

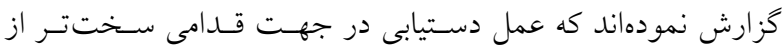

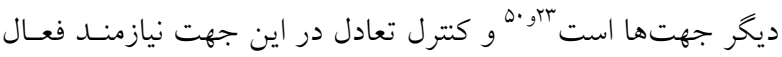

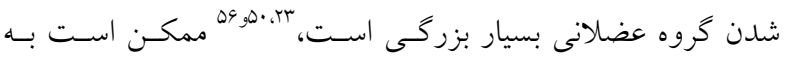
همين دلايل فاصله دستيابى در جهت قدامى بيشتر از ديخر جهتهـا كاهش يافته باشد.

\section{نتيجه گيرى}

به طور كلى كاهش تعادل و اختلال در كنترل عصبى - عضـلانى در اثر فعاليتهاى ANE، و ME SMIE خصوصا در SLS و جهـت قدامى رخ مى دهد. ميز ان كاهش تعادل ايستا و بويا در وضعيتهـاى مختلف كنترل تعادل، احتمالا به باز يا بسته بودن جششمهـا، بِايـدارى و نايايدارى سطح اتكا، مساحت سطح اتكا، وضعيت بدنى كه تعادل

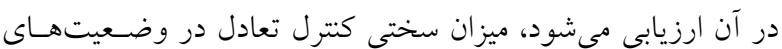
كوناكون، تفاوت در ميزان كنترل عصبى - عضلانى مورد نيـاز بــراى
فاصلهى دستيابى و مقدار فلكشن زانو در تمامى جهتهـاى SEBT مى گردد. "rاما تمامى يافتهاى قبلى بالى با نتايج ما همسو نبودند، مونجو و همكاران نشان دادند كه در اثر خستخى ممكىن اسـت كـه اخـتلال مكانيكى مانند كاهش شتاب حركت رخ دهد اما مكانيزمهـاى يـيش انتظارى كتترل تعادل بدون تغيير بـاقى بمانــد. هـا ايسن نتـايج نشـان مىدهد كه سيستم عصبى مركزى استراتزىهاى كنترل قامت را تغيير

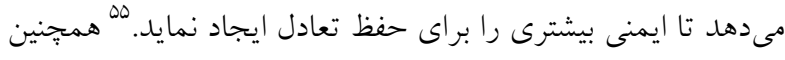
زامكوا و همكاران كاهش تعـادل معنسى دارى روى صـفحهى يايسـار بعد از فعاليت ورزشى با حسداكثر (تعادل ايست (Stable Platform)

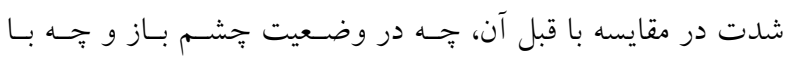
جشمان بسته كزارش نكردند.

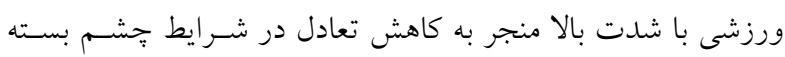

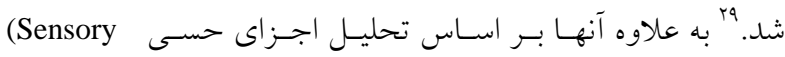
كنترل تعادل نشان دادند كـه سيسـتم دهليـزى بيشـتر از Analysis) سيستم حس بيكرى بعد از فعاليت با شدت حداكثر تحت تاثير قرار مى كيرد. يافتهاى ما نشان داد كه ميزان كاهش تعادل ايستا روى BESS به وضعيت و سطحى كه تعادل در آن كنترل مىشـود بسـتخى دارد. هيج كدام از فعاليتها منجر به افزايش تعداد خطاهـا در DLS روى سطح سخت نشدند، به نظر مىرسد كه تعادل ايستا در اين وضعيت

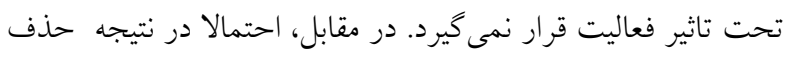

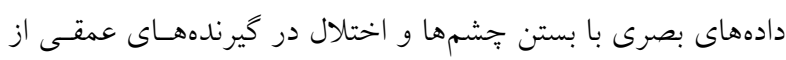
طريق اعمال خستخى و سطح نـرم، عملكــرد در BESS روى سـطح نرم در وضعيت DLS بعد از تمامى فعاليـتهـا كـاهش يافـت. هـم راستا با نتايج ما، گزارش شده زمانى كه دادههـاى بصـرى حــذف و

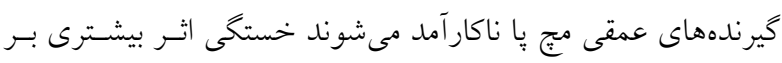
تعادل دارد.

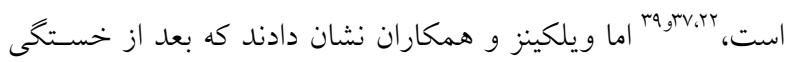
ناشى از فعاليت ورزشسى تركيبى تعـادل در وضـعيت DLS دجّـار

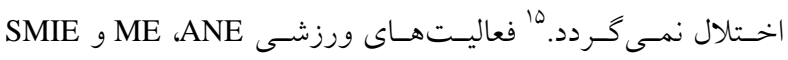
بيشترين اثر را هنخام حفظ تعادل ايسـتا روى هـر دو سـطح نـرم و سخت بر SLS داشتند. احتمـالا، كـم بـودن مسـاحت سـطح اتكـا، وضعيت بدن در فضا (ايستادن روى يكى پـا و دستها روى كمـر) و حذف دادهاى بينايى حفظ تعادل را در اين شرايط نسبت به ديخـر 


$$
\begin{aligned}
& \text { درستى داشته باشند. هم:جنين، مربيان ورزشى بهتر است كـه برنامـه }
\end{aligned}
$$

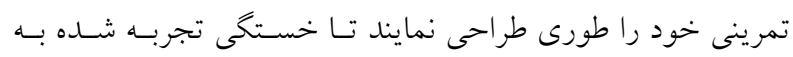

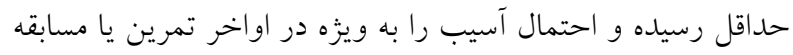

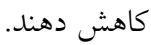

\section{References}

1. Winter, D., Patla, A., Frank, J.S. Assessment of balance control in humans. Med Prog Technol 1990;16(1-2): 3151.

2. Susco, T., McLeod, T., Valovich, B., Gansneder, M., and Shultz, J. Balance recovers within 20 minutes after exertion as measured by the balance error scoring system. Journal of Athletic Training 2004 ;39(3): 241 - 246.

3. Kejonen, P., K. Fysiatian, et al. Body Movements During Postural Stabilization: Measurements with a Motion Analysis System, University of Oulu. 2002. http://herkules.oulu.fi/isbn9514267931/html/index.html.

4. Shumway, C., and Woollacott, M.H. Motor control: theory and practical applications. Second Edition. Lippincott Williams \& Wilkins. 2000

5. Guskiewicz, K., and Perrin, D. Effect of orthotics on postural sway following inversion ankle sprain. Journal of Orthopedic and Sports Physical Therapy 1996;23(5): 326331.

6. Hoffman, M., and Payne, V. The effects of proprioceptive ankle disk training on healthy subjects. The Journal of orthopaedic and sports physical therapy 1995 ;21(2): 90 93.

7. Konradsen, L., and Ravn, J. Prolonged proneal reaction time in ankle instability. International Journal of Sports Medicine 1991;12(3): 290 - 292.

8. Lentell, G., Katzman, L., and Walters, M.R. The Relationship between Muscle Function and Ankle Stability. The Journal of orthopaedic and sports physical therapy 1990;11(12): $605-611$.

9. Tropp, H., Ekstrand, J., and Gillquist, J. Stabilometry in functional instability of the ankle and its value in predicting injury. Med Sci Sports Exerc 1984;16(1): 6466.

10. Irrgang, J., Whitney, S., and Cox, D.E. Balance and proprioceptive training for rehabilitation of the lower extremity. Journal of Sport Rehabilitation 1994;3(1): 6883.

11. Lentell, G., Baas, B., Lopez, D., McGuire, L., Sarrels, M., Snyder, P. The contributions of proprioceptive deficits, muscle function, and anatomic laxity to functional instability of the ankle. The Journal of orthopaedic and sports physical therapy 1995;21(4): 206 - 15.

12. Wilkerson, G. Biomechanical and neuromuscular effects of ankle taping and bracing. Journal of Athletic Training

$$
\begin{aligned}
& \text { حفظ تعادل در وضعيتهاى مختلف و نوع فعاليـت ورزشـى انجـام }
\end{aligned}
$$

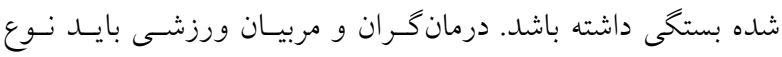

$$
\begin{aligned}
& \text { فعاليت انجام شده و وضعيتى كه قرار است تعادل در آن حفظ گردد }
\end{aligned}
$$

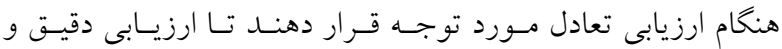

$$
\text { 2002;37(4): } 436 \text { - } 445 .
$$

13. Valovich, T. and T. Christina .The Use of the Standardized Assessment of Concussion and the Balance Error Scoring System and Learning Effects in Youth Sports Participants. Dissertation, University Microfilms International. 2002

14. Riemann, B., and Guskiewicz, K. Effects of mild head injury on postural stability as measured through clinical balance testing. Journal of Athletic Training 2000; 35(1): $19-25$.

15. Wilkins, J., McLeod, T., Perrin, D.H., and Bruce, M. Gansneder.Performance on the balance error scoring system decreases after fatigue. Journal of Athletic Training 2004;39(2): 156 - 161.

16. Lorist, M., Kernell, D., Meijman, T.F., and Zijdewind, I. .Motor fatigue and cognitive task performance in humans. The Journal of Physiology 2002;545(1): 313-319.

17. Hargreaves, M. and L. Spriet. Exercise metabolism, Human Kinetics Publishers. Second edition. 2006:163 185.

18. Fitts, R. Muscle fatigue: the cellular aspects. American journal of sports medicine 1996;24(6 Suppl): S9-13.

19. Abutaleb Enas E, Mohamed Assmaa H. Effect of induced fatigue on dynamic postural balance in healthy young adults. Bulletin of Faculty of Physical Therapy. 2015; 20(2): 161-167.

20. Baroni BM, Wiest MJ, Generosi RA, Vaz MA, Junior L, Pinto EC. Effect of muscle fatigue on posture control in soccer Players during the short-pass movement. Revista Brasileira de Cineantropometria \& Desempenho Humano 2011; 13: 348-53.

21. Ochsendorf, D., Mattacola, C., and Brent L.A. Effect of orthotics on postural sway after fatigue of the plantar flexors and dorsiflexors. Journal of Athletic Training 2000;35(1): 26 - 30.

22. Johnston, R., Howard, M., Cawley, P.W., Losse, G.M., Hughston, C., Atlanta, G.A. Effect of lower extremity muscular fatigue on motor control performance. Medicine \& Science in Sports \& Exercise 1998;30(12): 1703 1707.

23. Gribble, P. A., Hertel, J., Denegar, C.R., and Buckley, W.E. The effects of fatigue and chronic ankle instability on dynamic postural control. Journal of Athletic Training 2004; 39(4): 321- 329. 
24. James W. Bellew, Beth L. Panwitz, Laura Peterson, Mary C. Brock, Katie E. Olson, William H. Staples. Effect of Acute Fatigue of the Hip Abductors on Control of Balance in Young and Older Women, Archives of Physical Medicine and Rehabilitation 2009; 90( 7) : 1170 $-1175$.

25. Hossein Negahban, Malihe Etemadi, Saeed Naghibi, Anita Emrani, Mohammad Jafar Shaterzadeh Yazdi, Reza Salehi, Aida Moradi Bousari, The effects of muscle fatigue on dynamic standing balance in people with and without patellofemoral pain syndrome, Gait \& Posture 2013; 37( 3) : 336-339.

26. Evan V. Papa, K. Bo Foreman, Leland E. Dibble, Effects of age and acute muscle fatigue on reactive postural control in healthy adults, Clinical Biomechanics 2015; 30 (10): 1108-1113.

27. Marcel J.P. Toebes, Marco J.M. Hoozemans, Joost Dekker, Jaap H. van Dieën, Effects of unilateral leg muscle fatigue on balance control in perturbed and unperturbed gait in healthy elderly, Gait \& Posture 2014 ; 40( 1): 215-219.

28. Thierry Paillard, Effects of general and local fatigue on postural control: A review, Neuroscience \& Biobehavioral Reviews 2012; 36( 1): 162-176.

29. Zemkov, E., Viitasalo, J., Hannola, H., Blomqvist, M., Konttinen, N., Mononen, K. The Effect of Maximal Exercise on Static and Dynamic Balance in Athletes and Non-Athletes. Medicina Sportiva 2007;11(3): 70-77.

30. Derave, W., Tombeux, N., Cottyn, J., Pannier, J.L., and De Clercq, D. Treadmill exercise negatively affects visual contribution to static postural stability. International journal of sports medicine 2002;23(1): 44-49.

31. H. Hassanlouei, L. Arendt-Nielsen, U.G. Kersting, D. Falla, Effect of exercise-induced fatigue on postural control of the knee, Journal of Electromyography and Kinesiology 2012; 22( 3): 342-347.

32. Zemkova, E. Parameters of balance after exercise bouts with different energy yield from anaerobic glycolysis. Abstract book of the 1st Visegrad Congress of Sports Medicine "Medical Problems of Contemporary Sport". Štrbske Pleso: Slovak Society of Sports Medicine \& Slovak Olympic Committee in collaboration with National Institute of Sport. 2002

33. Donath L1, Zahner L, Roth R, Fricker L, Cordes M, Hanssen H, Schmidt-Trucksäss A, Faude O. Balance and gait performance after maximal and submaximal endurance exercise in seniors: is there a higher fall-risk? Eur J Appl Physiol. 2013;113(3):661-9.

34. Alias HA, Justine M. The Impact of a Submaximal Level of Exercise on Balance Performance in Older Persons. The Scientific World Journal 2014;2014:986252.

35. William Johnston, Kara Dolan, Niamh Reid, Garrett F.
Coughlan, Brian Caulfield, Investigating the effects of maximal anaerobic fatigue on dynamic postural control using the Y-Balance Test, Journal of Science and Medicine in Sport, 2017. (In Press).

36. N. Cortes, J. Onate, S. Morrison, Differential effects of fatigue on movement variability, Gait \& Posture 2014; 39( 3): 888-893.

37. Lepers, R., Bigard, A., Diard, J.P., Gouteyron, J.F., and Guezennec, C.Y. Posture control after prolonged exercise. European journal of applied physiology and occupational physiology 1997;76(1): 55 - 61.

38. Nardone, A., Tarantola, J., Galante, M., and Schieppati, M. Time course of stabilometric changes after a strenuous treadmill exercise. Archives of physical medicine and rehabilitation 1998;79(8): 920-924.

39. Nardone, A., Tarantola, J., Giordano, A., and Schieppati, M. Fatigue effects on body balance. Electro encephalography and Clinical Neuro physiology / Electro myography and Motor Control 1997;105(4): 309-320.

40. Ageberg, E., Roberts D., Holmströmand, E., \& Fridén, T. Balance in single-limb stance in healthy subjects reliability of testing procedure and the effect of shortduration sub-maximal cycling. BMC musculoskeletal disorders 2003; 4(1): 14.

41. Vuillerme, N., Nougier, V., and Prieur, J.M. Can vision compensate for a lower limbs muscular fatigue for controlling posture in humans? Neuroscience Letters 2001;308(2): 103-106.

42. Conconi, F., Ferrari, M., Ziglio, P.G., Droghethi, P., \& Codea, L. Determination of the anaerobic threshold by a noninvasive field test in runners. American physiological Society 1982;52(4): 869 - 873.

43. Seliga, R., Bhattacharya, A., Succop, R., Wickstrom, D., and Smith, K. Effect of work loan and respirator wear on postural stability, heart rate, and perceived exertion. American Industrial Hygiene Association Journal 1991;52(10): 417-422.

44. Robertson, R., Moyna, N., Millich, N.B., Goss, FL., and Thompson, P.D. Gender comparison of RPE at absolute and relative physiological criteria. Medicine \& Science in Sports \& Exercise 2000;32(12): 2120 - 2129.

45. Mahon, A., Duncan, G., Howe, C.A., and Corral D.P. Blood lactate and perceived exertion relative to ventilatory threshold: boys versus men. Medicine \& Science in Sports \& Exercise 1997;29(10): 1332 1337.

46. Gribble, P.A., and Kaminski, T. Research digest. The star excursion balance test as a measurement tool. Athletic Therapy Today 2003;8(2): 46-47.

47. Fox, Z., Mihalik, J., Blackburn, JT., Battaglini, C.L., and Guskiewicz, K,M. Return of postural control to baseline after anaerobic and aerobic exercise protocols. Journal of Athletic Training 2008;43(5): 456. 
48. Valovich, T., Perrin, D., and Gansneder, B.M.Repeat administration elicits a practice effect with the Balance Error Scoring System but not with the Standardized Assessment of Concussion in high school athletes. Journal of Athletic Training 2003; 38(1): 51 - 56.

49. Plisky, P., Gorman, P., Robert, J., Kyle, B., Kiesel, PT., Frank, B., Underwood, PT. and Bryant, E. The Reliability of an Instrumented Device for Measuring Components of the Star Excursion Balance Test. North American Journal of Sports Physical Therapy: NAJSPT 2009;4(2): 92 - 99.

50. Gribble, P. A., and J. Hertel. Considerations for normalizing measures of the Star Excursion Balance Test. Measurement in Physical Education and Exercise Science 2003; 7(2): 89-100.

51. Hertel, J., Braham,R., Hale, S.A., and Olmsted-Kramer, L.C. Simplifying the star excursion balance test: analyses of subjects with and without chronic ankle instability. The Journal of orthopaedic and sports physical therapy 2006; 36(3): 131 - 137.
52. Theurel, J. and R. Lepers . Neuromuscular fatigue is greater following highly variable versus constant intensity endurance cycling. European Journal of Applied Physiology 2008; 103(4): 461-468.

53. Simoneau, M., Bégin, F., and Teasdale, N. The effects of moderate fatigue on dynamic balance control and attentional demands. Journal of neuroengineering and rehabilitation 2006; 3(1): 22.

54. Sarshin, A., Sadeghi, H., Abbasi, A. The Effect of Activity Related Fatigue on Dynamic Postural Control As Measured By the Star Excursion Balance Test. Journal of Biomechanics 2007; 40(2): 706.

55. F. Monjo, N. Forestier, Electrically-induced muscle fatigue affects feedforward mechanisms of control, Clinical Neurophysiology 2015; 126( 8): 1607-1616.

56. Earl, J., and Hertel, J. Lower-extremity muscle activation during the Star Excursion Balance Tests. Journal of Sport Rehabilitation 2001;10(2): 93-104. 